\title{
Shock Resistance Improvement of Carbon Steel Carabiners Used at PPE
}

\author{
Diana-Petronela Burduhos-Nergis ${ }^{1}$, Andrei-Victor Sandu ${ }^{1,2}$, Dumitru-Doru Burduhos- \\ Nergis ${ }^{1}$, Doru-Costin Darabont ${ }^{3}$, Radu-Ioachim Comaneci ${ }^{1}$, and Costica Bejinariu, ${ }^{1, *}$ \\ 1"Gheorghe Asachi" Technical University of Iasi, 67 Dimitrie Mangeron Blv., Iasi 700050, Romania \\ ${ }^{2}$ Romanian Inventors Forum, 3 Sf. P. Movila St., 700089 Iasi, Romania \\ ${ }^{3}$ INCDPM „Alexandru Darabont”, 35A Ghencea Blv, Bucharest 061692, Romania
}

\begin{abstract}
In a continuously changing world where the human operator still plays an important role in most industrial activities, health and safety occupies a fundamental place, with the goal of maintaining workers healthy and in safe condition during their job activities. One of the means that make this goal achievable is the use of adequate personal protective equipment. The carabiners are connecting parts that link the components quickly and reversibly of personal protective equipment used against falls. Thus shackles can be divided in multiple elements, such as: the gate, which always opens inward and can be provided with or without the locking system, the second and the biggest element is the body which can have different form according to the BS EN 12275:2013 standard, the gate and the body are connected thru the rivet pin and nose. The personal fall arrest system used in areas such as construction, speleology, petroleum industry, includes metal components that must possess high mechanical properties, especially shock-resistance. In order to improve resilience, a layer of rubber paint will be deposited on the carabiner surface. The aim of this study is to analyse the influence of rubber coating on the carabiners shock resistance.
\end{abstract}

\section{Introduction}

Personal Protective Equipment (PPE) includes any type of equipment used by workers in order to protect them from certain occupational hazards specific to the activities they are required to perform daily or in certain exceptional circumstances [1].

According to current legislation, in areas where technical measures do not provide enough protection, the employer must provide personal protective equipment to workers. In order to be worn or used safely by users, personal protective equipment must meet the following requirements: comply with occupational health and safety specifications, provide protection without inducing a new risk, be appropriate to the respective working conditions, be ergonomic and adjustable or fit to the worker $[2,3]$.

Before choosing the personal protective equipment, it should be evaluated the risks which cannot be avoided by collective protective measures. This assessment establishes the

*Corresponding author: costica.bejinariu@yahoo.com 
necessary characteristics that the personal protective equipment must have in order to provide protection for workers [4].

As the employer do, the worker has multiple obligations when it is using the personal protective equipment, such as:

- to know the characteristics and how to use the PPE, which are provided in specific standards or in the instruction for user sheet.

- to wear the all the PPE during the entire job activity;

- to use PPE only for the purpose for which it was created and to be concerned with preserving their protective qualities;

- to submit PPE to the periodic checks, cleaning or detoxification provided in the instructions for user sheet;

- to request a new PPE when, for various reasons, the PPE in use no longer presents the qualities of protection for which it was granted [5].

Fall arrest equipment are required when workers perform their activities at high heights, especially in places where there is a danger of falling. Lack of a proper equipment, inappropriate use or degraded equipment can lead to serious accidents. Another consequence related to inappropriate use of carabiners is dropping it from different heights. A fall protection system includes all the items and components fitted in a given order either for the purpose of preventing or stopping the user to fall from height [6].

There are multiple components in a fall arrest system, such as: anchoring devices (designed to provide an anchor point to which a safety rope or fall arrester retractable can be attached), positioning belts (aiming to positioning the worker during work and must be used as a body support), fall arrester used with an energy absorber (are designed to retrieve and absorb the kinetic energy resulting from a fall), accessories (which have the role to improv the working conditions by ensuring the ergonomic availability of tools or by improving body protection during work effort) and connectors (carabiners or hooks) [7].

The standard recommendation for fall arrest equipment are specified by Directive 89/686/EEC and European Standards for Personal Protective Equipment (PPE) [8].

A carabiner is a special type of metal link, used to connect and reconnect the components of the fall arrest systems [9]. The components of a carabiner are presented in Figure 1.

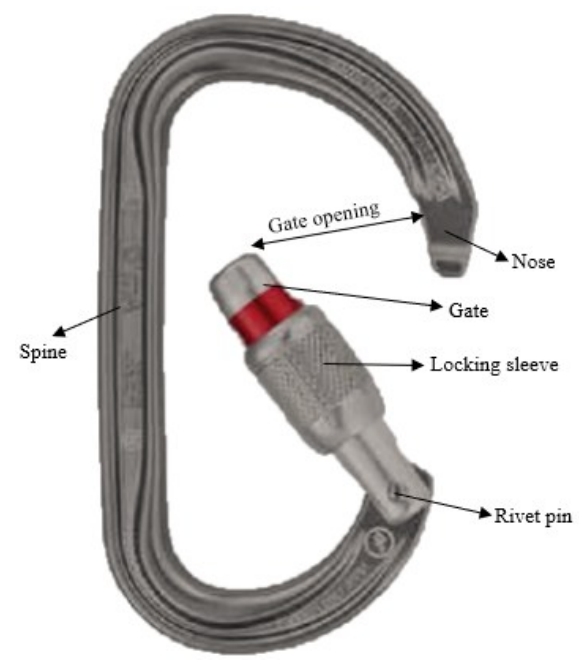

Fig. 1. The main components of a carabiner 
Carabiners are used in different areas, such as: civil engineering, industry, speology or rescue operations. According to the place where thus are used there are two main types of materials used for carabiners manufacturing. Due to the low density, aluminum carabiners are used especially by athletic climbers. Therefore, in places where the tensile properties or refractory strength are important, the base material is replaced by steel for carabiners manufacturing [10].

There are a multitude of factors that can influence a carabiner properties, therefore, material selection is a major stage in carabiners manufacturing process. One of the factors that can influence the properties of a carabiner is the material toughness. Because thus hooks are used at heights, they can be dropped or stroke by different bodies which can affect its properties due to the microcracks appearance.

Another factor which must be taken in to consideration is the temperature. Carabiners must withstand at high temperature differences, for example from $-40{ }^{\circ} \mathrm{C}$ during the Everest escalation to $500{ }^{\circ} \mathrm{C}$ when are used by firefighters during their missions.

Carabiners are connecting elements which get in contact with the rope or another carabiner, so the friction coefficient is an important factor that influences the elements durability (carabiner and other elements that come into contact with). A high friction coefficient, due to a large roughness, can lead to rope premature wear.

Due to the areas in which carabiners are used (sailing, industry, rescue operations), they can get in contact with various corrosive substances, so one very important factor which must be taken into consideration is its specific corrosion resistance [11].

\section{Rubber coating - shock resistance}

One of the main steels used by carabiner-manufacture companies is 1045 steel, (SAE J1397, 1992). In our study we have used an equivalent steel, the C45 steel, with the chemical composition presented in Table 1.

Table 1. The chemical composition of $\mathrm{C} 45$ samples

\begin{tabular}{|c|c|c|c|c|c|c|c|}
\hline Element & $\mathrm{Fe}$ & $\mathrm{C}$ & $\mathrm{Si}$ & $\mathrm{Mn}$ & $\mathrm{P}$ & $\mathrm{Cu}$ & $\mathrm{Cr}$ \\
\hline \%, wt. & balance & 0.45 & 0.22 & 0.98 & 0.02 & 0.15 & 0.17 \\
\hline
\end{tabular}

This steel belongs to the class of carbon steels (also called common steels), which can be defined as iron containing, in addition to carbon, other residuals elements except those added for deoxidation (silicon or aluminum) and those added to counteract the detrimental effects of sulfur (manganese or chromium).

In order to keep the production costs low, the carbon steel surface must be improved by covering with different layer by using simple and economical methods.

One important method of increasing the corrosion resistance properties of carbon steel carabiners is zinc phosphate deposition by conversion [12]. The phosphating process is one of the most commonly used corrosion protection techniques, being a simple and economical process, which doesn't require highly qualified staff or expensive raw materials $[13,14]$.

After deposition of the phosphate layer, an improvement of the corrosion resistance properties of $\mathrm{C} 45$ steel was observed of about $33 \%$ when exposed to the fire extinguishing solution and $46 \%$ when exposed to salt water [15].

Because of the microcracks appearance, when a carabiner is dropped or stroked from different heights, it is recommended to be replaced. In this paper we've analyzed the possibility of coating the carabiner surface with a rubber paint in order to absorb the shocks and reduce or even eliminate the risk of microcracks appearance. To improve the corrosion 
and shock resistance properties of a carabiner, it must be phosphate and painted as shown in Figure 2.

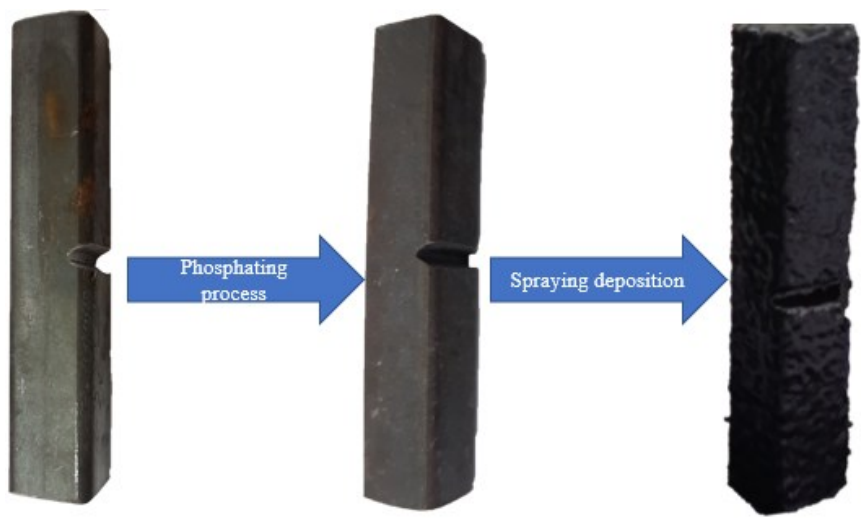

Fig. 2. Process flow of $\mathrm{C} 45$ carabiners covering.

The rubber paint used in this study is usually used to cover specific vehicles parts in order to provide stone chip protection and it can be applied by spraying.

\subsection{Microstructural analysis}

The deposited rubber paint and phosphate layers were analyzed by means of a Zeiss optical microscope and of a Vega Tescan LMH II scanning electron microscope.

As can be seen in Figures 3 (b) and $4(a, b)$, the phosphate layer has a porous surface due to the formation of interdental crystalline dendrites, which has the advantage of covering it with different paints types.

The painted samples present a relatively porous uniform surface that can be seen in Figures 3 (a) and 4 (c,d), this can lead to a high friction coefficient. Therefore, our proposal is to cover just the exterior surface of the carabiner in order to protect it against mechanical shocks and, in the same time, to maintain the specific sliding properties of phosphate layer.
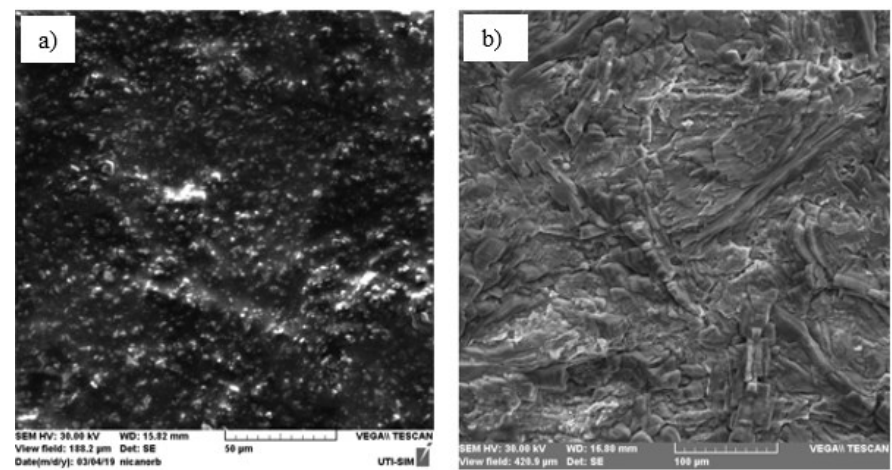

Fig. 3. SEM micrographs of layers: (a) Rubber paint layer SEM micrography, $50 \mu \mathrm{m}$; (b) Phosphate layer SEM micrography, $100 \mu \mathrm{m}$. 

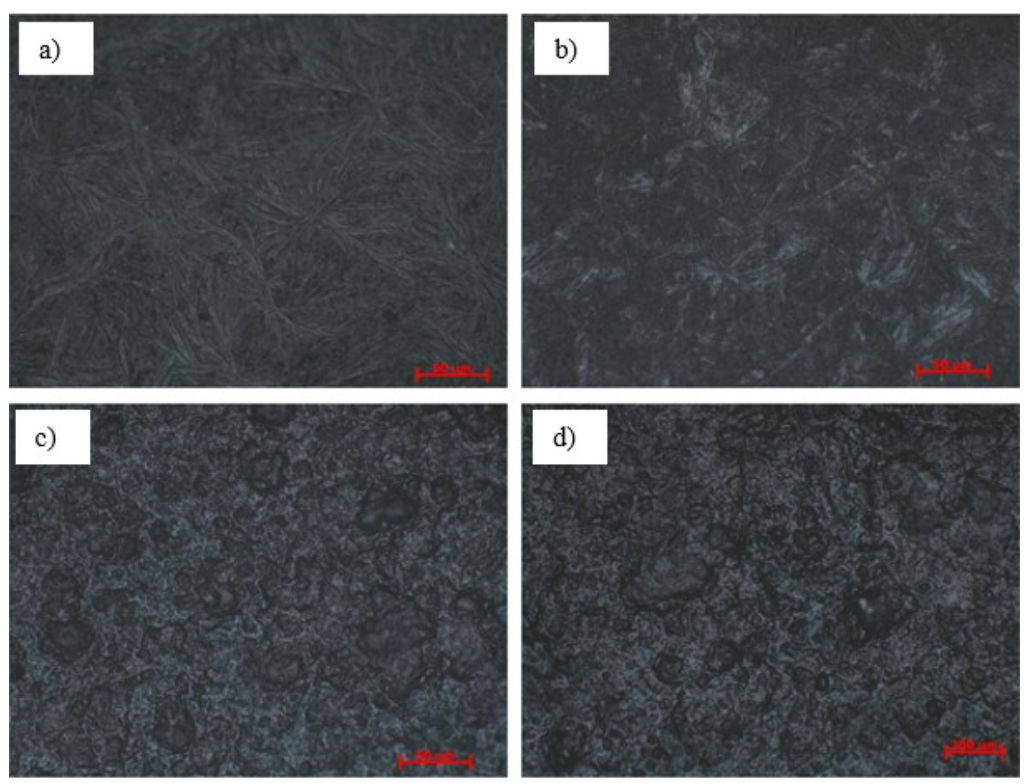

Fig. 4. Optical microstructure: (a, b) phosphate layer microstructure, X50; (c) rubber painted layer microstructure, X50; (d) rubber painted layer microstructure, X200.

\subsection{Mechanical analysis}

The insoluble phosphate layer provides high protection against corrosion and the rubber paint layer can absorb mechanical shocks that can lead to internal cracks. Surface coating with a black rubber paint represents a cheap, simple and fast way to increase the impact resistance of C45 steel carabiners. The exterior layer possess high elasticity, does not cracker break and adheres very well to the phosphate layer specific porous surface.

The impact resistance was determined using a shock hammer pendulum - Charpy Hammer, according to EN 10045-1: 1990, on samples with dimensions specified in Figure 5.

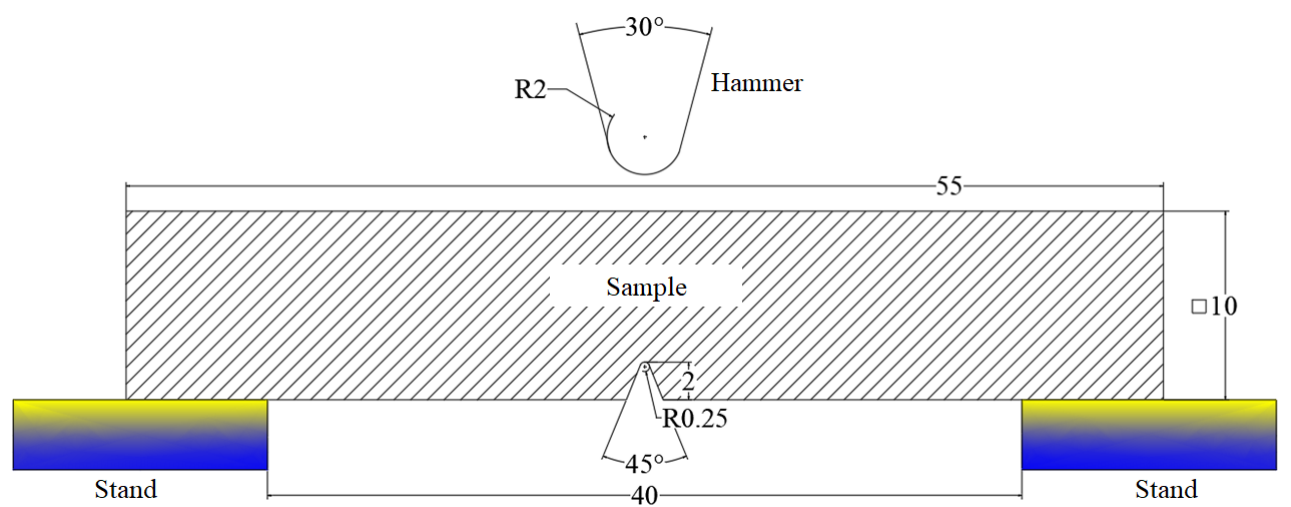

Fig. 5. Schematic representation of samples and hammer

By coating with a phosphate layer the impact resistance of samples is positively influenced, by increasing the samples value from $166 \mathrm{KJ}$ specific to the initial sample to $182 \mathrm{KJ}$. The samples covered with a rubber paint presents the most significant increase, from $182 \mathrm{KJ}$ specific to phosphate samples to $209 \mathrm{KJ}$, as shown in Figure 6. 


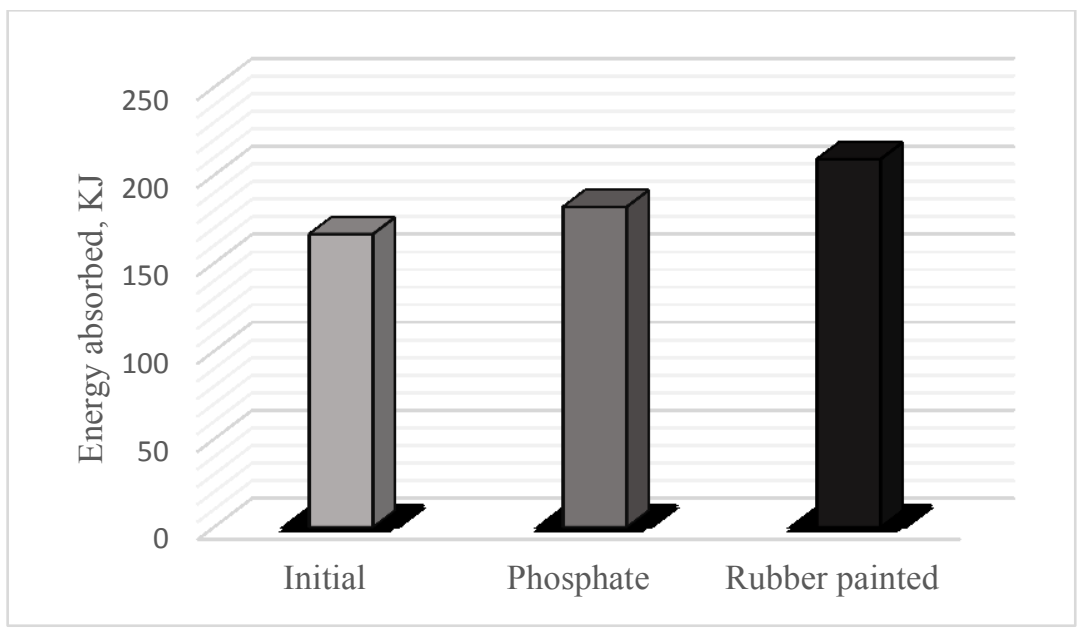

Fig. 6. Tested samples toughness

\section{Conclusions}

Surface coverage of C45 samples with an insoluble phosphate layer positively influences the corrosion resistance of carabiners exposed to fire-extinguishing solution and salt water and also support the deposition of a rubber paint layer due to its high specific porosity.

By covering the samples with a rubber paint layer, an increase of the impact resistance is obtained due to the shock-absorbing properties of the deposition.

Due to its specific high friction coefficient of the rubber paint coating, the carabiner must be covered only on the exterior part, in order to avoid the exfoliation of the layer upon contact with the rope or other elements (piton, carabiner, anchor, etc.).

Phosphate layer increases the impact resistance with approximately $9 \%$, and by rubber painting the energy absorbed is increased up to $15 \%$. After covering the $\mathrm{C} 45$ samples with two layers, the impact resistance of the initial sample increases up to $26 \%$.

\section{References}

1. C. Bejinariu, D.C. Darabont, E.R Baciu, I.S. Georgescu, M.A Bernevig-Sava, C. Baciu, Sustainability, 9 (2017)

2. C. Bejinariu, D.C. Darabont, E.R. Baciu, I. Ionita, M.A.B. Sava, C. Baciu, Environ. Eng. Manag. J., 16 (2017)

3. D.C. Darabont, R.I. Moraru, A.E. Antonov, C. Bejinariu, Qual.-Access Success, 18 (2017).

4. D.C. Darabont, R.I. Moraru, A.E. Antonov, C. Bejinariu, E D P Sciences: Cedex A, 121 (2017)

5. G. B. Babut, R. I. Moraru, Access to Success, 19 (2018)

6. G. B. Babut, R. I. Moraru, C. Lucian-Ionel, Proceedings of the 5th International Conference on Manufacturing Science and Education Sibiu, Romania, II (2011)

7. R. I. Moraru, G. B. Babut, L. I. Cioca, Geoconference on Science and Technologies in Geology, Exploration and Mining, Sgem, I (2013)

8. B.-S. Mihai-Adrian, I. Iulian, B. Constantin, D. D. Costin, L. Alexandru, C. A. Marian, B. Costica, Qual.-Access Success, 18 (2017) 
9. D.P.B. Nergis, C. Nejneru, D.C. Achitei, N. Cimpoesu, C. Bejinariu, Iop Publishing Ltd, Bristol (2018)

10. T. Evans, S. Truebe, A Review of Webbing Anchor Research, International Technical Rescue. Symposium, Portland, Oregon (2015)

11. V. Scott, Design of a Composite Carabiner for Rock Climbing (Final Year Project, Mechanical Engineering, Imperial College London, 2008)

12. A.V. Sandu, C. Bejinariu, I.G. Sandu, M.M.A.B. Abdullah, Thin Phosphate Film Characterization Methods and Techniques, in: Modern Technologies of Thin Films Deposition: Chemical Phosphatation (Materials Research Forum Llc, Millersville, 2018)

13. C.D. Florea, I. Carcea, R. Cimpoesu, S.L. Toma, I.G. Sandu, C. Bejinariu, Rev. Chim., 68 (2017)

14. C.D. Florea, C. Munteanu, N. Cimpoesu, I.G. Sandu, C. Baciu, C. Bejinariu, Rev. Chim, 68 (2017)

15. D.-P. Burduhos-Nergis, C. Nejneru, D.-D, Burduhos-Nergis, C. Savin, A.V. Sandu, S.L. Toma, C. Bejinariu, Rev. Chim. 70 (2019) 